\title{
Torsion Gelometry of Cheese ${ }^{1}$
}

\author{
M. H. Tunick and D. L. Van Hekken \\ *U.S. Department of Agriculture, Agricultural Research Service, Eastern Regional Research Center, \\ 600 E. Mermaid Lane, Wyndmoor, PA 19038
}

\section{ABSTRACT}

Torsion gelometry, a fundamental rheological test in which specimens are twisted until they fracture, was applied to several different cheese varieties to determine its suitability for measuring their textural properties. Fresh and aged Brick, Cheddar, Colby, Gouda, Havarti, Mozzarella, and Romano cheeses were subjected to torsion analysis, and the results were compared with those from small amplitude oscillatory shear (SAOS) tests and texture profile analysis (TPA). Strong relationships (correlation coefficients $>0.8$ ) were found between torsion shear stress and TPA hardness, and between torsion shear strain and TPA cohesiveness. SAOS, which measures rheological properties of intact samples, did not correlate well with torsion or TPA. A map showing trends during aging toward brittle, mushy, rubbery, and tough texture was drawn using the torsion data. The findings show that torsion gelometry provides fundamental rheological data on cheese at the fracture point. The information can be used to compare textural qualities of cheese samples as they are being cut.

(Key words: cheese, oscillatory shear, texture profile analysis, torsion gelometry)

Abbreviation key: $\mathbf{G}^{\prime}=$ storage modulus, $\mathbf{G}^{\prime \prime}=$ loss modulus, $\mathbf{G}^{*}=$ complex modulus, $\eta^{*}=$ complex viscosity, $\sigma_{\max }=$ torsion shear stress at failure, $\gamma_{\max }=$ torsion shear strain at failure, MNFS = moisture in nonfat substance, SAOS = small amplitude oscillatory shear, TPA $=$ texture profile analysis.

\section{INTRODUCTION}

The three categories of food texture measurement are empirical, imitative, and fundamental tests (Scott Blair, 1958). Empirical tests involve test conditions that

Received January 2, 2002

Accepted May 8, 2002.

*Corresponding author: M. H. Tunick; e-mail: mtunick@ arserrc.gov.

${ }^{1}$ Mention of brand or firm name does not constitute an endorsement by the U.S. Department of Agriculture over others of a similar nature not mentioned. cannot usually be compared with those of more rigorous experiments. Imitative tests such as texture profile analysis (TPA) utilize a universal testing machine to mimic chewing; these tests can also be considered empirical, as there are no corrections for changes in the shape of the specimen. TPA is useful for making comparisons, but does not measure true rheological properties. Fundamental tests, such as small amplitude oscillatory shear (SAOS), use specific specimen geometries and instruments, allowing systematic analysis of the results. Stress and strain are linearly dependent on each other and the sample does not fracture or change shape in SAOS tests, which provide data on viscoelastic properties including storage modulus $\left(\mathbf{G}^{\prime}\right)$, loss modulus $\left(\mathbf{G}^{\prime \prime}\right)$, and complex viscosity ( $\left.\boldsymbol{\eta}^{*}\right)$ (Tunick, 2000).

Another fundamental test, torsion gelometry, was developed for use on food gels at North Carolina State University (Diehl et al., 1979). In a torsion test, specimens are twisted in a viscometer, with the shear stress $\left(\sigma_{\max }\right)$ and shear strain $\left(\gamma_{\max }\right)$ being measured at the fracture point. In analysis of cheese, specimens are milled into a capstan shape so that the fracture takes place at the narrow center of the specimen. Fracture can occur in compression, shear, or tension mode, which are imposed at equal magnitudes in different directions (Hamann and Foegeding, 1994). Torsion gelometry has been used to analyze a number of foods and food gels (Hamann, 1983) and has been correlated with sensory ratings by a texture profile panel (Montejano et al., 1986; Gwartney et al., 2002). A comparison of torsion gelometry, TPA, and sensory texture of various gels showed that the highest correlations among instrumental parameters were observed between shear stress and TPA hardness, and shear strain and TPA cohesiveness (Montejano et al., 1986). Torsion gelometry is gaining more widespread use because improvements in the technique have reduced the difficulties previously involved in sample preparation and analysis. Torsion gelometry has recently been applied to cheese (Foegeding et al., 1998) and was compared to vane rheometry in tests on Cheddar, Mozzarella, and processed cheeses (Truong and Daubert, 2001). Their results indicated that Cheddar, the hardest cheese they tested, exhibited the highest shear stress; and Mozzarella, the most elastic cheese in their experiments, exhibited the highest 
shear strain. Another study compared torsion gelometry of low- and full-fat Monterey Jack, Cheddar, and American cheeses to texture scores from a sensory panel (Gwartney et al., 2002). Fracture stress and strain were each significantly correlated with several sensory descriptors. These are the only cheese varieties that have been analyzed by torsion gelometry and reported in the literature.

A comparison of torsion gelometry, TPA, and SAOS rheology was recently performed on Mozzarella cheeses in our laboratory (Tunick et al., 2000). Since torsion gelometry measures fundamental rheological properties at the fracture point, it should prove valuable in analyzing cheese samples as they are being broken apart, such as when the consumer cuts or bites into them. Cheese production in the U.S. has been increasing for years, reaching $3.75 \times 10^{9} \mathrm{~kg}$ in 2000 (USDA, 2001), so reliable methods for characterizing the texture of this product will be important for those in the cheese industry. The object of this study was to develop torsion data for a variety of cheeses, and to compare the results with an imitative test (TPA) and another fundamental test (SAOS).

\section{MATERIALS AND METHODS}

Commercial cheeses were manufactured at the University of Wisconsin and shipped under refrigeration overnight. Cheese varieties consisted of fresh and aged Brick, Colby, Gouda, Havarti, and Romano; fresh, mild, medium, and sharp Cheddar; and Old Amsterdam, which is Gouda aged without the wax coating after 18 mo. The ages at analysis of the aged cheeses were above the minimums specified by the US Federal Standards of Identity (Table 1). Low moisture part skim Mozzarella cheeses prepared in our laboratory in a previous study (Tunick et al., 2000) were also included. There was one sample each of the fresh Brick, Havarti, and Romano, and two samples of each of the other cheeses.

Moisture content was determined by the forced draft oven method (AOAC International, 1997) and fat content by the modified Babcock test (Kosikowski and Mistry, 1997b). Moisture in nonfat substance (MNFS) was calculated as $100 \% \times(\%$ moisture $) /(100-\%$ fat $)$.

Rheological tests were conducted at $20-22^{\circ} \mathrm{C}$. TPA was performed as previously described (Tunick et al., 1991). Four cylinders measuring approximately $15 \mathrm{~mm}$ in diameter and $15 \mathrm{~mm}$ in height were cut from the samples and each was compressed twice by $75 \%$ in a Sintech 1/G universal testing machine (MTS Systems, Eden Prairie, MN) operating at a crosshead speed of $100 \mathrm{~cm} / \mathrm{min}$. Hardness, springiness, and cohesiveness were calculated by the instrument's software from the resulting force-distance curve, and these values were multiplied by each other to obtain chewiness values (Tunick, 2000). SAOS measurements were made as previously described (Tunick et al., 1990), with $\mathrm{G}^{\prime}, \mathrm{G}^{\prime \prime}$, and $\eta^{*}$ being determined in triplicate with a Rheometrics Dynamic Analyzer model RDA-700 (Rheometrics Scientific, Piscataway, NJ) at a frequency of $10 \mathrm{rad} / \mathrm{s}$.

Shear stress and shear strain values at point of fracture were determined in a torsion gelometer (Gel Consultants, Raleigh, NC) operating at $2.5 \mathrm{rpm}$. Four plugs were bored from the sample and milled to the appropriate capstan shape as described by Foegeding (1992). A specific milling configuration was used to insure that the specimens were uniform so that their geometry had minimal influence on the calculations. Shear rigidity, which is $\sigma_{\max } / \gamma_{\max }$, was also calculated.

The SAS Software System (SAS Institute, 1999) was used to obtain Pearson correlations and standard errors. A correlation is described as significant if $P<0.05$.

\section{RESULTS AND DISCUSSION}

\section{Composition}

Table 1 shows the varieties, ages, and compositions of the cheeses. The varieties included two surface ripened cheeses (Brick and Havarti), a pasta filata type (Mozzarella), three hard cheeses (Cheddar, Colby, and Gouda), and two varieties that become very hard with age (Old Amsterdam and Romano). The moisture contents of the aged Colby and Havarti cheeses were slightly higher than those specified in the Standards of Identity, but the moisture levels of the other cheeses and all of the fat levels were within the Standards. The cheeses in this study were selected in part because of their dissimilar compositions: the moisture levels were between 33.7 and $51.6 \%$, and the fat levels were between 18.1 and $36.0 \%$. The Romano became drier with storage, but the moisture and fat content of the other cheeses did not change appreciably. MNFS, which is essentially a ratio of water to protein and is related to firmness (Olson and Johnson, 1990), is also included and will be discussed later.

\section{Rheological Results}

Table 2 shows the rheological data. In the torsion results, the values for $\sigma_{\max }$ and $\gamma_{\max }$ were calculated by the following equations, where $\mathrm{K}=$ shape factor constant $=1.08, \mathrm{r}=$ minimum sample radius $=5 \mathrm{~mm}, \mathrm{M}=$ torque $(\mathrm{N} \mathrm{cm}), \phi=$ angular deformation of the curved section ( $\mathrm{rad})$, and $\mathrm{Q}=$ constant for the curved section $=8.45 \times 10^{-6} \mathrm{~m}^{-3}$ (Diehl et al., 1979):

$$
\sigma_{\max }=\frac{2 K M}{\pi r^{3}}
$$


Table 1. Average age and composition of cheese varieties tested, compared with US Federal Standards of Identity.

\begin{tabular}{|c|c|c|c|c|c|c|c|}
\hline \multirow[b]{2}{*}{ Variety } & \multicolumn{4}{|c|}{ This study } & \multicolumn{3}{|c|}{ Standards of identity ${ }^{1}$} \\
\hline & Age & Moisture & Fat & $\mathrm{MNFS}^{2}$ & $\begin{array}{l}\text { Minimum } \\
\text { age }\end{array}$ & $\begin{array}{l}\text { Maximum } \\
\text { moisture }\end{array}$ & $\begin{array}{l}\text { Minimum } \\
\text { fat }\end{array}$ \\
\hline & (d) & - & $(\%)-$ & - & (d) & $\longrightarrow(\%)$ & \\
\hline Brick, fresh & 7 & 38.5 & 33.0 & 57.5 & & & \\
\hline Brick, aged & 78 & 38.3 & 33.3 & 57.4 & 60 & 44 & 28.0 \\
\hline Cheddar, fresh & 12 & 37.7 & 33.5 & 56.7 & & & \\
\hline Cheddar, mild & 56 & 37.0 & 32.4 & 54.7 & & & \\
\hline Cheddar, medium & 197 & 38.2 & 31.3 & 55.6 & & & \\
\hline Cheddar, sharp & 379 & 36.3 & 34.8 & 55.7 & 60 & 39 & 30.5 \\
\hline Colby, fresh & 10 & 39.7 & 31.7 & 58.1 & & & \\
\hline Colby, aged & 202 & 40.5 & 30.8 & 58.5 & 60 & 40 & 30.0 \\
\hline Gouda, fresh & 38 & 37.7 & 36.0 & 58.9 & & & \\
\hline Gouda, aged & 154 & 40.4 & 32.0 & 59.4 & $\mathrm{a}$ & 45 & 25.3 \\
\hline Old Amsterdam & 566 & 38.0 & 33.0 & 56.7 & & & \\
\hline Havarti, fresh & 15 & 42.0 & 34.0 & 63.6 & & & \\
\hline Havarti, aged & 113 & 42.0 & 34.3 & 63.9 & $\mathrm{a}$ & 39 & 22.6 \\
\hline Mozzarella, fresh & 7 & 51.6 & 18.1 & 62.9 & & & \\
\hline Mozzarella, aged & 42 & 51.6 & 18.1 & 62.9 & $\mathrm{a}$ & 52 & 14.4 \\
\hline Romano, fresh & 34 & 36.3 & 26.6 & 49.5 & & & \\
\hline Romano, aged & 505 & 33.7 & 27.3 & 46.4 & 150 & 34 & 25.1 \\
\hline $\mathrm{SE}$ & & 1.2 & 1.3 & 1.1 & & & \\
\hline
\end{tabular}

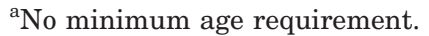

${ }^{1}$ Data from USFDA 2000.

${ }^{2}$ MNFS $=$ Moisture in nonfat substance.

$$
\gamma_{\max }=\frac{2 K \phi}{\pi r^{3} Q}
$$

Since shear stress is directly proportional to torque, the hardest cheeses, Romano and Old Amsterdam, had the highest values for $\sigma_{\max }$, as well as the highest shear rigidity values. Truong and Daubert (2001) also found that $\sigma_{\max }$ was dependent on the hardness, with Cheddar $>$ Mozzarella > processed cheese. Shear strain is dependent on angular deformation, and $\gamma_{\max }$ values for the Mozzarella are therefore high because Mozzarella is stretched during manufacture, which aligns the protein fibers and gives the cheese its characteristic deformability. This result is also in agreement with Truong and

Table 2. Torsion gelometry, texture profile analysis, and small amplitude oscillatory shear results for cheeses.

\begin{tabular}{|c|c|c|c|c|c|c|c|c|c|c|}
\hline \multirow[b]{2}{*}{ Variety } & \multicolumn{3}{|c|}{ Torsion } & \multicolumn{4}{|c|}{ Texture profile analysis } & \multicolumn{3}{|c|}{ Small amplitude oscillatory shear } \\
\hline & $\begin{array}{l}\text { Shear } \\
\text { stress } \\
(\mathrm{kPa})\end{array}$ & $\begin{array}{l}\text { Shear } \\
\text { strain }\end{array}$ & $\begin{array}{l}\text { Shear } \\
\text { rigidity } \\
(\mathrm{kPa})\end{array}$ & $\begin{array}{l}\text { Hardness } \\
(\mathrm{N})\end{array}$ & $\begin{array}{l}\text { Springiness } \\
(\mathrm{mm})\end{array}$ & Cohesiveness & $\begin{array}{l}\text { Chewiness } \\
(\mathrm{mJ})\end{array}$ & $\begin{array}{l}\text { Elastic } \\
\text { modulus } \\
(\mathrm{kPa})\end{array}$ & $\begin{array}{l}\text { Viscous } \\
\text { modulus } \\
(\mathrm{kPa})\end{array}$ & $\begin{array}{l}\text { Complex } \\
\text { viscosity } \\
(\mathrm{kPa} \cdot \mathrm{s})\end{array}$ \\
\hline Brick, fresh & 55.9 & 1.33 & 42.0 & 88.6 & 8.64 & 0.27 & 207 & 35.4 & 13.3 & 3.78 \\
\hline Brick, aged & 29.8 & 1.66 & 18.0 & 45.5 & 9.74 & 0.35 & 155 & 43.1 & 20.4 & 4.77 \\
\hline Cheddar, fresh & 42.9 & 0.83 & 51.9 & 46.5 & 8.57 & 0.21 & 83.7 & 75.3 & 30.0 & 8.13 \\
\hline Cheddar, mild & 53.4 & 1.28 & 41.7 & 46.4 & 9.13 & 0.21 & 89.0 & 77.2 & 32.4 & 8.38 \\
\hline Colby, fresh & 49.8 & 1.13 & 44.1 & 73.8 & 8.55 & 0.28 & 177 & 47.1 & 18.4 & 5.07 \\
\hline Colby, aged & 32.0 & 1.26 & 25.4 & 48.6 & 8.44 & 0.25 & 103 & 40.6 & 19.4 & 4.52 \\
\hline Gouda, fresh & 48.8 & 1.86 & 26.2 & 77.4 & 10.02 & 0.41 & 318 & 43.9 & 17.8 & 4.74 \\
\hline Gouda, aged & 21.8 & 1.65 & 13.2 & 34.5 & 9.68 & 0.34 & 114 & 30.7 & 18.0 & 3.57 \\
\hline Old Amsterdam & 98.1 & 0.44 & 223 & 96.4 & 11.44 & 0.11 & 121 & 83.7 & 38.7 & 9.29 \\
\hline Havarti, fresh & 40.7 & 1.27 & 32.0 & 56.9 & 10.16 & 0.39 & 225 & 83.3 & 25.6 & 8.72 \\
\hline Havarti, aged & 16.9 & 1.34 & 12.6 & 19.8 & 9.21 & 0.24 & 43.8 & 37.0 & 14.0 & 3.96 \\
\hline $\mathrm{SE}$ & 8.3 & 0.04 & 7.5 & 5.7 & 0.12 & 0.01 & 11.6 & 3.1 & 1.5 & 0.34 \\
\hline
\end{tabular}


Daubert (2001), who found that $\gamma_{\max }$ values for Mozzarella were higher than those for Cheddar or processed cheese. The cheeses in the torsion experiments fractured in the shear mode.

In TPA tests, specimens are subjected to uniaxial compression instead of angular deformation, causing failure of the specimen in the compression mode. TPA hardness is the maximum force during the first compression cycle, springiness is the height the sample recovers between the first and second compressions, and cohesiveness is the ratio of the positive force area of the second compression to that of the first (Tunick, 2000). These experiments showed that most of the cheeses became less hard and less cohesive with age; springiness did not display a significant trend. Proteolytic breakdown of $\alpha_{\mathrm{s} 1}$-casein into peptides causes cheese to soften and lose structural integrity with time (Fox, 1989). Consequently, the values for chewiness, defined as the amount of work required to masticate a solid food sample, usually decreased with storage. The Romano and the Gouda/Old Amsterdam cheeses are intended to become drier and harder with age, and their values for $\sigma_{\max }$, shear rigidity, hardness, and springiness increased with time. The cohesiveness of the Mozzarella, which has an elastic body, increased dramatically during storage as observed in previous experiments (Tunick et al., 1991). The cohesiveness of the Brick, which is also supposed to be elastic when ready for consumption (Olson, 1969), also increased. The aged Havarti had the lowest hardness and $\sigma_{\max }$; its curds are suspended in diluted whey when salt is added, which partially solubilizes the protein and softens the structure (Kosikowski and Mistry, 1997a).

SAOS differs from torsion tests because stress and strain are varied harmonically with time at a frequency $\omega$ on intact specimens. $G^{*}$, the complex modulus, is the ratio of the maximum stress to the maximum strain, and is the total energy required to deform the specimen. In purely elastic and in purely viscous samples, the strain and the resulting stress are out of phase by $0^{\circ}$ and $90^{\circ}$, respectively. In viscoelastic substances such as cheese, the stress and strain are out of phase by an angle $\delta$, which is between $0^{\circ}$ and $90^{\circ}$. The storage modulus is a measure of the energy stored in a sample during a SAOS deformation cycle, the loss modulus is a measure of the energy lost as heat, and the complex viscosity provides information on viscoelastic flow (Tunick, 2000). These parameters are related to $G^{*}$ as follows:

$$
\begin{gathered}
\mathrm{G}^{\prime}=\mathrm{G}^{*} \cos \delta \\
\mathrm{G}^{\prime \prime}=\mathrm{G}^{*} \sin \delta \\
\eta^{*}=\mathrm{G}^{*} / \omega
\end{gathered}
$$

SAOS results on cheese samples are dependent on the number and strength of the bonds between the casein particles, the structure of those particles, and the spatial distribution of the strands making up those particles (Roefs et al., 1990). For instance, the $G^{\prime}, G^{\prime \prime}$, and $\eta^{*}$ values for the Colby samples were much smaller than those of the Cheddar samples of the same age. These cheeses are manufactured in a similar manner except that Colby curd is stirred and not cheddared. As a result, the curd particles in Colby do not knit as well as in Cheddar, leading to weaker interactions between the casein strands. The $\mathrm{G}^{\prime}$ value for the Havarti decreased greatly with age because air holes are incorporated between the curd grains in the manufacture of Havarti, and $\mathrm{CO}_{2}$ production during ripening expands these holes (Nielsen, 1993). The SAOS results for all of the cheeses followed the same general trends as the torsion and TPA results, increasing with age for Gouda/ Old Amsterdam and Romano and usually decreasing with age for the other varieties.

\section{Correlations Between Methods}

Table 3 shows correlations among the rheological and compositional parameters. Shear rigidity was strongly correlated with shear stress (coefficient of 0.899). Shear stress, which is the force required for fracture, also showed a strong positive correlation (0.859) with hardness, which measures the force needed to attain a given deformation. Montejano et al. (1986) observed the same result with their protein gel preparations, concluding that the two tests were similar in their ability to measure strength characteristics. Shear strain exhibited a strong positive correlation (0.818) with cohesiveness, a result also observed by Montejano et al. (1986). Both parameters reflect the deformability of a food. Shear rigidity, an indication of stiffness, showed a fairly strong positive correlation (0.713) with hardness but only a moderate negative correlation $(-0.422)$ with cohesiveness. These results indicate that torsion gelometry provides a fundamental alternative to TPA in characterizing the texture of cheese.

The correlation coefficients between TPA springiness and the other instrumental parameters were all between -0.24 and 0.22 . Springiness measures recovery after a specimen is compressed, and is not analogous to torsion or SAOS parameters. The correlation coefficients between cohesiveness, chewiness, and the SAOS parameters were all between -0.28 and 0.26 . Chewiness is proportional to hardness, and the correlation coefficient between the two was 0.822 .

$\mathrm{G}^{\prime}, \mathrm{G}^{\prime \prime}$, and $\eta^{*}$ were highly correlated with each other (> 0.88), but not with the other parameters. $G^{\prime \prime}$ had moderate correlations (between -0.41 and 0.51 ) with 
the torsion values, but otherwise the SAOS parameters had correlations between -0.38 and 0.38 with the torsion and TPA values. SAOS yields information on shortrange interactions of intact specimens, and is not useful in predicting behavior of cheese as it fractures.

\section{Variations with MNFS}

Moisture in nonfat substances (MNFS) has been cited as the most important variable affecting cheese quality (Pearce and Gilles, 1979). MNFS exhibited moderate positive correlations (both 0.55) with $\gamma_{\max }$ and cohesiveness, and strong negative correlations (both $-0.80)$ with $\sigma_{\max }$ and hardness. MNFS showed weaker negative correlations (between -0.32 and -0.45 ) with chewiness, $\mathrm{G}^{\prime}, \mathrm{G}^{\prime \prime}$, and $\eta^{*}$. The correlation with springiness was low. The casein in cheese becomes more hydrated as MNFS increases, which has been shown in Mozzarella to result in lower hardness, $\mathrm{G}^{\prime}, \mathrm{G}^{\prime \prime}$, and $\eta^{*}$ values (Tunick et al., 1993). $\sigma_{\max }$ and shear rigidity would be expected to decrease as well. Cohesiveness and $\gamma_{\max }$ were directly related to MNFS because casein hydration results in a more cohesive gel.

Comparisons of moisture with the torsion and TPA data produced lesser correlations than the corresponding comparisons with MNFS; the comparisons between moisture and the SAOS data produced slightly better correlations. Except for springiness, fat content did not correlate with the rheological data as well as MNFS. These results indicate that MNFS is a better predictor of texture than percentage of moisture or fat.

\section{Variations with Storage Time}

Storage time (age) exhibited moderate positive correlations with shear rigidity (0.431) and springiness (0.476), and moderate negative correlations with $\gamma_{\max }$ $(-0.552)$ and cohesiveness $(-0.535)$. The correlations with the SAOS parameters were lower $(<0.39)$. When only fresh and aged Romano, fresh Gouda, and Old Amsterdam were considered, the correlation coefficient between hardness and age was 0.449 , and between $\sigma_{\max }$ and age was 0.471. As previously mentioned, these cheeses become drier and harder with storage. Among the other cheeses, which soften with time because of proteolysis, the correlation coefficient between hardness and age was -0.474 , and between $\sigma_{\max }$ and age was -0.453 .

\section{Texture Map}

A texture map, which is a plot of shear stress vs. shear strain, provides a graphical representation of product texture (Truong and Daubert, 2001). Maps illustrating 


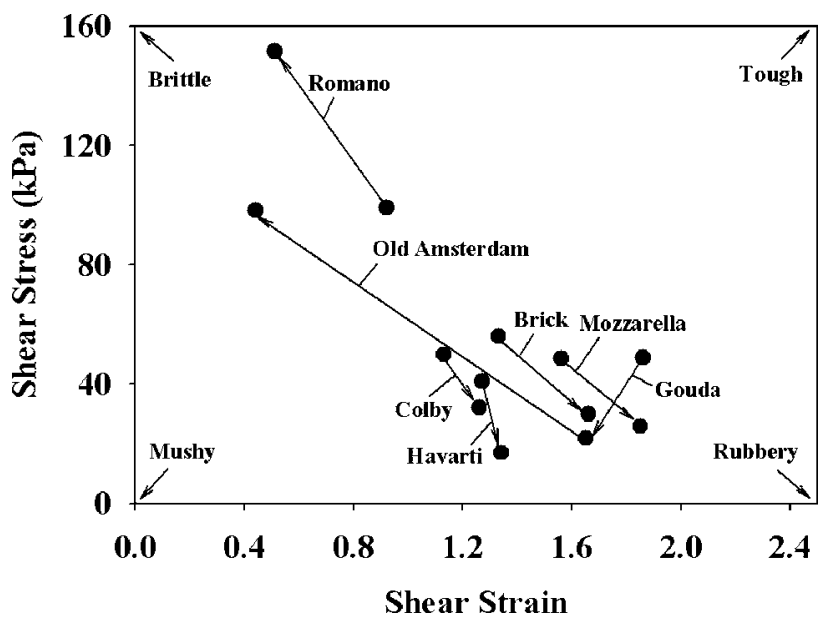

Figure 1. Texture map of commercial Brick, Colby, Gouda, Havarti, and Old Amsterdam cheeses. Part skim Mozzarella cheese from a previous study (Tunick et al., 2000) is also included. Arrows point from the fresh cheeses to the corresponding aged cheeses, indicating textural changes with storage.

the textural changes in the cheeses with age are shown in Figures 1 and 2. Foods exhibiting low $\sigma_{\max }$ are termed mushy if $\gamma_{\max }$ is low (a better descriptor for cheese would be "soft"), and rubbery if $\gamma_{\max }$ is high. Foods with high $\sigma_{\max }$ values can be considered brittle if $\gamma_{\max }$ is low, and tough if $\gamma_{\max }$ is high. The Romano and Old Amsterdam, which lost moisture with age, became much more brittle. The Gouda was softer after 5 mo aging; the Cheddar initially became tougher with age, but then became softer as proteolysis broke down the protein matrix (Figure 2). The Brick, Colby, Havarti, and Mozzarella all became more rubbery as they aged. The Brick and

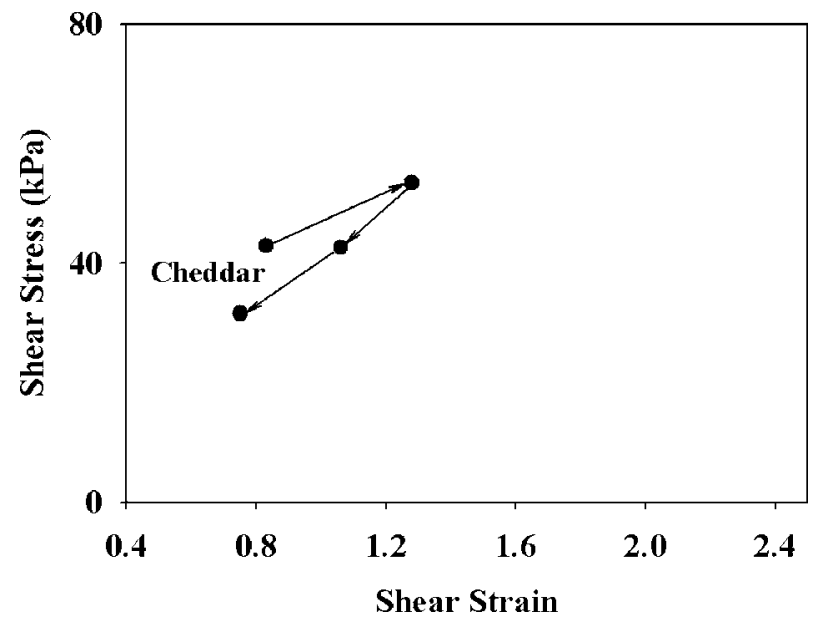

Figure 2. Texture map of commercial Cheddar cheese. Arrows point from fresh to mild to medium to sharp Cheddar.
Mozzarella, the two relatively elastic varieties, showed a more pronounced change.

Information from a texture map such as this one is useful to food scientists who wish to relate parameters such as aging and composition to stress and strain of the product at fracture. These mechanical properties are important to consumer perception, and torsion gelometry provides a systematic method of measuring them.

\section{CONCLUSIONS}

Torsion gelometry provides fundamental rheological data on cheese at the fracture point. Testing of a number of cheeses of different types and ages reveals that torsion shear stress is highly correlated with TPA hardness, and torsion shear strain with TPA cohesiveness. Torsion tests can be used to characterize textural attributes that are meaningful to food scientists and consumers.

\section{ACKNOWLEDGMENTS}

The authors thank Bill Klein, University of Wisconsin, for supplying the cheese samples, James Shieh for performing some of the compositional analyses, and John Phillips for assistance in statistical analysis.

\section{REFERENCES}

AOAC International. 1997. Method 948. 12 in Official Methods of Analysis. 16th edition. AOAC International, Gaithersburg, MD.

Diehl, K. C., D. D. Hamann, and J. K. Whitfield. 1979. Structural failure in selected raw fruits and vegetables. J. Text. Stud. 10:371-400.

Foegeding, E. A. 1992. Rheological properties of whey protein isolate gels determined by torsional fracture and stress relaxation. J. Text. Stud. 23:337-348.

Foegeding, E. A., H. Li, and S. R. Bottcher. 1998. Gelation of globular proteins. Pages 253-271 in Phase/State Transitions in Foods. M. A. Rao and R. W. Hartel, ed. Marcel Dekker, New York.

Fox, P. F. 1989. Proteolysis during cheese manufacture and ripening. J. Dairy Sci. 72:1379-1400.

Gwartney, E. A., E. A. Foegeding, and D. K. Larick. 2002. The texture of commercial full-fat and reduced-fat cheese. J. Food Sci. 67:812-816.

Hamann, D. D. 1983. Structural failure in solid foods. Pages 351383 in Physical Properties of Foods, M. Peleg, E. B. Bagley, ed. AVI Publ., Westport, CT.

Hamann, D. D., and E. A. Foegeding. 1994. Analysis of torsion, compression and tension for testing food gel fracture properties. http:// www.gelconsultants.com/torsion.html.

Kosikowski, F. V., and V. V. Mistry. 1997a. Page 266 in Cheese and Fermented Milk Foods. Vol. 1. 3rd edition. F. V. Kosikowski LLC, Westport, CT.

Kosikowski, F. V., and V. V. Mistry. 1997b. Pages 212-214 in Cheese and Fermented Milk Foods. Vol. 2. 3rd ed. F. V. Kosikowski LLC, Westport, CT.

Montejano, J. G., D. D. Hamann, and T. C. Lanier. 1986. Comparison of two instrumental methods with sensory texture of protein gels. J. Text. Stud. 16:403-424.

Nielsen, E. W. 1993. Danish Cheese Varieties. Pages 247-251 in Cheese: Chemistry, Physics and Microbiology. Vol. 2. Major 
Cheese Groups. P. F. Fox, ed. Chapman and Hall, London, United Kingdom.

Olson, N. F. 1967. Page 19 in Ripened Semisoft Cheeses. Chas. Pfizer \& Co., New York.

Olson, N. F. and M. E. Johnson. 1990. Light cheese products: Characteristics and economics. Food Technol. 44(10):93-96.

Pearce, K. N., and J. Gilles. 1979. Composition and grade of Cheddar cheese manufactured over three seasons. N.Z. J. Dairy Sci. Technol. 14:63-71.

Roefs, S. P. F. M., T. van Vliet, H. J. C. M. van den Bijgaart, A. E. A. de Groot-Mostert, and P. Walstra. 1990. Structure of casein gels made by combined acidification and rennet action. Neth. Milk Dairy J. 44:159-188.

SAS Institute, Inc. SAS/STAT User's Guide. Version 8. 1999. SAS Inst., Inc., Cary, NC.

Scott Blair, G. W. 1958. Rheology in food research. Adv. Food Res. 8:1-61.

Truong, V. D., and C. R. Daubert. 2001. Textural characterization of cheeses using vane rheometry and torsion analysis. J. Food Sci. 66:716-721.
Tunick, M. H. 2000. Rheology of dairy foods that gel, stretch, and fracture. J. Dairy Sci. 83:1892-1898.

Tunick, M. H., K. L. Mackey, P. W. Smith, and V. H. Holsinger. 1991. Effects of composition and storage on the texture of Mozzarella cheese. Neth. Milk Dairy J. 45:117-125.

Tunick, M. H., K. L. Mackey, J. J. Shieh, P. W. Smith, P. Cooke, and E. L. Malin. 1993. Rheology and microstructure of low-fat Mozzarella cheese. Int. Dairy J. 3:649-662.

Tunick, M. H., E. J. Nolan, J. J. Shieh, J. J. Basch, M. P. Thompson, B. E. Maleeff, and V. H. Holsinger. 1990. Cheddar and Cheshire cheese rheology. J. Dairy Sci. 73:1671-1675.

Tunick, M. H., D. L. Van Hekken, P. W. Smith, E. L. Malin, and V. H. Holsinger. 2000. Characteristics of Mozzarella cheeses made from fortified milk or nonfat dry milk. Milchwissenschaft 55:450-453.

USDA, National Agricultural Statistics Service. 2001. Page 2 in Dairy Products 2000 Summary. USDA, Washington, DC.

USFDA. 2000. Code of Federal Regulations, Title 21, Part 133. USFDA, Washington, DC. 